University of Nebraska - Lincoln

DigitalCommons@University of Nebraska - Lincoln

Spanish Language and Literature

Modern Languages and Literatures, Department

2012

\title{
Mother's Social Network and Family Language Maintenance
}

Isabel Velázquez

University of Nebraska-Lincoln, mvelazquez2@unl.edu

Follow this and additional works at: https://digitalcommons.unl.edu/modlangspanish

Part of the Spanish and Portuguese Language and Literature Commons

Velázquez, Isabel, "Mother's Social Network and Family Language Maintenance" (2012). Spanish Language and Literature. 103.

https://digitalcommons.unl.edu/modlangspanish/103

This Article is brought to you for free and open access by the Modern Languages and Literatures, Department of at DigitalCommons@University of Nebraska - Lincoln. It has been accepted for inclusion in Spanish Language and Literature by an authorized administrator of DigitalCommons@University of Nebraska - Lincoln. 
Published in Journal of Multilingual and Multicultural Development (2012),

doi: 10.1080/01434632.2012.720984

Copyright $(\subset 2012$ Taylor \& Francis. Used by permission.

http://www.tandfonline.com/doi/abs/10.1080/01434632.2012.720984

Submitted April 9, 2012; revised July 30, 2012; published online September 13, 2012.

\title{
Mother's Social Network and Family Language Maintenance
}

\author{
Isabel Velázquez
}

\begin{abstract}
Department of Modern Languages and Literatures, University of Nebraska-Lincoln, 1127 Oldfather Hall, PO Box 880315, Lincoln NE 68588-0315, USA; email mvelazquez2@unl.edu
\end{abstract}

\begin{abstract}
This article reports the results of a social network analysis (SNA) performed on the mother's primary network of interaction in 15 Mexican American families in the city of El Paso, Texas, the neighborhood of La Villita, in Chicago, and the city of Lincoln, Nebraska. The goal of this study was to examine potential opportunities for Spanish use by her children as well as sources of information and influence that might shape her views about the benefits and drawbacks of linguistic maintenance in her family. The network features of primary language of exchange, density, strength of ties, level of integration to local, regional and transnational networks and gender segregation were examined. Results suggest that in these families Spanish transmission is influenced by mother's perception of benefit/cost, mother's participation in networks where Spanish is vested with social capital, and mother's linguistic competence.
\end{abstract}

Keywords: Spanish, language maintenance, Mexican American families, social networks

\section{Introduction}

This article examines mother's social network (SN) as related to Spanish language maintenance in a group of Mexican American (MexAm) families in three communities in the USA. Research on parenting and child development outlines direct and indirect ways in which the structure of a parent's SN impacts his or her performance as a parent. Cochran (1990), for example, describes three mechanisms through which this process takes place. First, network members might provide general, emotional and instrumental support to parents as developing adults. Second, certain network actors have the potential to impact parental attitudes and behaviors by encouraging or criticizing specific parenting behaviors. Finally, actors who are parents themselves can model effective parenting behavior (Cochran 1990, 14). Importantly, Cochran distinguishes between direct and indirect mechanisms of influence. In the former, network membership influences the parent, while the latter involves face-to-face interaction between the child and one or more network actors - with changes occurring in the child as a function of this interaction (17). If transmission of a family language is conceptualized - as it is here, as one of the many tasks potentially involved in raising children in bilingual households - it follows 
then that success or failure in this endeavor is influenced both directly and indirectly by parental networks. ${ }^{1}$ Examination of parental networks in minority-language families, for example, can help us understand how the structure of a parent's network impacts opportunities for exposure to the family language for the children. Additionally, it can help us examine the sources of information and influence that might contribute to shaping parents' views about the benefits and drawbacks of maintenance. Parental perceptions are particularly relevant for transmission, and involve not only estimations of cost/benefit, but also self-perceptions of agency as well. As De Houwer $(1999,83)$ points out, the best chances for active bilingualism are commonly present in families where parents have a positive impact belief concerning their own role in the child's acquisition process. This project was influenced by Fishman (1991, 2000), for whom minority languages will only be able to survive and grow if they are cemented through intergenerational transmission in "the realm of intimacy - home, family, neighborhood, friendship, immediate community" $(2000,4)$.

\section{Mother's social network}

Although the 15 families included in this study constituted two-parent households, the analysis discussed in the following pages focuses specifically on the mother's closest network of interaction for several reasons. Previous studies have pointed to the centrality of the mother in intergenerational minority language transmission (Okita 2002; Potowski and Matts 2008; Velázquez 2009). Other authors, such as González, Moll, and Amanti (2005), highlight the role of women in the formation of household and community networks and funds of knowledge. Because they bore the primary responsibility for daily childrearing tasks, and because they regulated much of their children's schedules, activities and opportunities for interaction outside the home, the mothers in these families played a fundamental role in family language planning. ${ }^{2}$ Further, it will be argued here that in immigrant households, parents - and in particular mothers - must negotiate transnational and local pressures either to foster bilingualism in their family, or encourage subtractive assimilation to English.

\section{Social network analysis}

The concept of SN will be understood here using Walker, MacBride, and Vachon's (1977, 35) early but useful definition: "The set of personal contacts through which the individual maintains his social identity and receives emotional support, material aid and services, information and new social contacts" (In Maguire 1983, 14). Social network analysis (SNA) will be defined as the study of the social structure that individuals and entities construct through interaction. SNA is a way to understand how individuals or entities access and share social capital - that is, material, informational and symbolic resources. SNA is also an instrument to investigate how network structure affects an individual's everyday behavior (Hawe, Webster, and Shiell 2004). As Daming, Xiaomei, and Wei (2008) explain, an individual's position in this structure provides him or her with a social locale. This is relevant for attitude formation, because this locale determines the information that individuals are exposed to and the type of social events in which they participate (Daming, Xiaomei, and Wei 2008, 273). The analysis described here was not conducted using a whole-network approach; its goal was not to determine the structural characteristics of respondents' entire network of personal interaction. Rather, this analysis was egocentric, 
and focused on the type and content of ties that bound respondents to their closest network of interaction or, more specifically, on respondents' subjective cognition of ties (Hawe, Webster, and Shiell 2004).

\section{Social networks and social capital}

The concept of social capital is useful when trying to understand the ways in which a speaker's personal network can exert influence on his or her attitudes about language use and transmission. Degenne and Forsé $(1999,115)$ remind us that when speaking about personal networks, the concept of social capital is not a metaphor: "These are resources people can invest and spend. Individuals also barter economic, political and symbolic resources, even if only economic resources have strict cash equivalence. (. . .) social capital consists of an individual's personal network and her chances of accessing whatever is circulating there, e.g., information."

\section{The study of social networks in multilingual communities}

SNA has a long tradition within sociolinguistic studies. Early studies using a whole-network approach attempted to map out the relationship between network participation and use of non-standard variants (Bortoni-Ricardo 1985; Eckert 1988). The whole-network approach to SNA has also been used to study processes of shift in language contact situations (Gal 1979). Perhaps the most well-known application of SNA in sociolinguistics is Milroy's (1987) ego-centered analysis of phonological variation and network membership in three working-class neighborhoods in Belfast, Ireland. Milroy found that strongest ties correlated with strongest use of vernacular variants. Following Granovetter's seminal strength of weak ties argument (1973), Milroy posits that weak ties are important channels for linguistic and social innovation because they serve as bridges across groups, while strong ties lead to intra-group cohesion and support of localized norms. SNA has been particularly useful for researchers investigating language maintenance and shift in immigrant communities because, as Daming, Xiaomei, and Wei $(2008,268)$ argue, SNA allows comparison of individual differences in the degree of integration in relationships that express normative pressures on social behaviors. Several studies have focused, for example, on adult maintenance and attrition as related to network participation in middle-class immigrant communities (Ripley Smith 2002; Stoessel 2002). Zentella (1997) studies a bilingual Puerto Rican neighborhood in New York City and concludes that language choice is influenced by gender and age-related networks, and that these networks act as a support system for its members. Wei (1994) investigates exchange, interactive and passive network ties, together with a number of ethnic and peer actors, as a way to understand patterns of language choice and language shift in three generations of Chinese families in the UK. Lanza and Svendsen (2007) discuss several studies related to family language use and personal networks in a Filipino community in Oslo, Norway, and find that parent's language choice at home correlates with the number of co-ethnic actors in their network. However, these authors find no statistical support for a relationship between ethnicity in the parents' network and children's language choice in the home (Lanza and Svendsen 2007, 289). The present study differs from Lanza and Svendsen (2007) because it focuses specifically on mother's SN and compares different network structures in three communities with higher demographic density of Spanish speakers than the speakers of Filipino languages in Oslo. More recently, Matsumoto (2010) employs SNA as an explanatory 
framework to study maintenance and shift in postcolonial Palau, in the western Pacific. She finds a strong relationship between amount of Japanese-oriented ties in respondents' SNs and the likelihood of Japanese use, and a negative correlation between Japanese ties and shift to English. Additionally, Matsumoto finds that even within the same community, SNs were the most important predictor of language behavior for only one of the three types of families she studied because of their different social experiences. Based on the research literature, a prediction was made before the start of data collection. This prediction was that tightly bound, dense networks of competent speakers of Spanish would foster use and transmission of Spanish.

\section{Method}

The analysis presented in this article is part of a larger study on intergenerational Spanish transmission in a group of MexAm families in three US communities. Data for the original study were collected using five instruments intended to gather information regarding perceptions of ethnolinguistic vitality; attitudes and motivations toward use and transmission; family practices that could foster or hinder Spanish development; reported household language use, and mother's SN. These were used during two interviews with the mother, conducted in respondents' homes, in Spanish, by a female bilingual who was a native speaker of Spanish (Velázquez 2008). Because of space constraints, only results related to language use and mothers' SN are discussed here. Results from that larger study suggest that families which provided their children with greater opportunities to develop competence in Spanish were those in which the mother perceived this language as an important component of their children's identity, and as an instrument to access economic opportunities.

In order to understand the types of ties that bound respondents to their closest network of interaction, five features were measured: primary language of exchange, density, strength of ties, integration to local, regional and transnational networks and degree of gender segregation. Language of exchange was examined in an attempt to understand the role of Spanish by network and cluster. Density and strength of ties were measured to understand network structure. Because 13 of the 15 participants in this study were immigrants, integration to local, regional and transnational networks was measured in an attempt to tease apart respondents' participation in networks that could increase opportunities of maintenance of the home language through linguistic re-contact. Gender segregation was measured to investigate the potential relevance of gender as related to language use within each network.

Respondents were asked to identify their five closest friends and five closest relatives not living in their household, plus five individuals whom they saw more than twice in a normal week - respondents were told that they could name fewer or more actors according to their individual circumstance. This was intended to work as a name and acquaintance generator. For Hawe, Webster, and Shiell (2004), name generator techniques frequently elicit strong ties in dense network sectors. Acquaintance generator techniques tend to elicit weaker ties - that is, with actors who exert less influence, but have greater potential to introduce new ideas (Hawe, Webster, and Shiell 2004, 972). Naming acquaintances is intended to elicit what Wei (1994) would identify as interactive ties, which may involve frequent interactions, but are not likely to result in exchange of resources. Name generator techniques can elicit both exchange and passive ties. For Wei (1994) and Mat- 
sumoto (2010), exchange and interactive ties involve mostly face-to-face interaction, while passive ties involve actors who are geographically distant and do not interact regularly with the respondent. An important difference here is that in this study, geographical location did not determine the strength of a tie. A respondent could perceive, for example, that it was impossible to exchange resources with an estranged relative who lived down the street, or could routinely exchange resources with someone who lived in another country through the use of remittances. This study seeks to expand Wei's (1994) definition of exchange network by offering a finer-grained analysis by strength of tie as related not only to material conditions, but also to respondents' subjective cognition of ties.

Network density was measured by dividing the number of concrete exchanges by the number of possible exchanges. A concrete tie was understood as a tie through which the respondent had exchanged resources. This differs from traditional definitions of density, which has been measured as the ratio of existing links to possible links (Degenne and Forsé 1999; Hawe, Webster, and Shiell 2004). Early researchers in the field understood existing link as that between two actors who know one another (Granovetter 1973; Maguire 1983). Under this definition, a density score of 1 would describe a network where everyone knows everyone else but has not necessarily exchanged resources. The decision to measure density in terms of concrete exchanges versus how many actors know each other is anchored in Paldam (2001), who argues that density is weighted by the strength and importance of the tie that binds two actors. In other words, Paldam suggests that participants' opportunities to access resources depend on their social capital, not only on the number of people they know. Under our definition, a density score of 1 would describe a network where every actor knows every other actor and has provided and received support from every other actor. This hypothetical network would be highly norm-enforcing, considering the high level of interdependence among its members. A distinction must be made here between density and plexity. In a highly dense network all actors know one another-and, under our present definition, have exchanged resources, while in a highly multiplex network all actors are related by something other than knowing the respondent. A network can of course be both highly dense and highly multiplex, but need not be. Data on network plexity were collected but not included in the final analysis as it is more relevant to whole-network analyses, and less so for ego-centered approaches such as the present one. Only a brief comparison of plexity by community, followed by a potential explanation for these differences, is presented in the discussion. Data on the type of resources most commonly exchanged-for example, economic, influence/information, emotional, etc. - were obtained by asking respondents if they had engaged in any of the following with the actors in their network: Lent or borrowed money, provided or received help to solve a problem, gave or asked for advice before making an important decision, and called when sad, worried or depressed.

Strength of ties. For each potential exchange, respondents were asked to select from the following options: I have done this with/for this person, I have not, but I would, if necessary, and I would never do this with/for this person. This was intended to investigate respondents' subjective cognition of ties. Active or exchange ties, in which the respondent had exchanged resources, were given a score of 2. Virtual or passive ties, which the respondent believed could be activated if needed, were given a score of 1 . Exchanges perceived by the respondent as not possible received a score of 0 . The difference between this and previous definitions of strength of ties is subtle but important when examining the potential influence of network actors. Consider, for example, a hypothetical network A and a hypothetical 
network B with equal number of actors and identical density scores. If respondent A believes that she could potentially activate all passive ties if needed, and respondent $B$ believes that she could not, their subjective cognition of their position in the network would be quite different.

Primary language of exchange was determined by asking respondents to identify the language-Spanish, English, Both, or Other, most commonly used with every member of their closest network of interaction, and then estimating the percentage of actors for each language in each community.

Integration to local, regional and transnational networks was determined by asking respondents about the physical location of each actor in their network. El Paso and Ciudad Juárez, México were considered part of the same border region.

Degree of gender segregation was measured by determining the percentage of female and male actors in respondents' closest network beyond their household. Male actors were further classified as related or unrelated to the respondent.

\section{The families and the communities}

The communities in this study exemplify the diversity of sociolinguistic environments that characterize the MexAm experience. The city of El Paso, Texas (EP), is the third oldest site of Spanish/English contact in the USA, and has a sustained history of bilingualism, and high ethnolinguistic vitality for Spanish. At the time of data collection, $71 \%$ of all El Pasoites older than five years spoke Spanish at home (US Census Bureau, ACS n.d.). La Villita or Little Village, in Chicago, is an ethnolinguistic enclave that is home - with the adjoining neighborhood of Pilsen and the city of Cicero - to the largest MexAm population outside the Southwest. La Villita (LV) participants lived in census tracts where $74-92 \%$ of people above five years old spoke Spanish at home. The city of Lincoln (LN) is the capital of the state of Nebraska, and has a recent history of Latino settlement and low ethnolinguistic vitality for Spanish. At the time of data collection only $4.2 \%$ of all persons over the age of five spoke Spanish at home.

Five families from each community participated in this study. All were two-parent households with at least one child under 18 living at home. Parents were native speakers of Mexican or MexAm Spanish and, in 13 of these 15 households, interacted exclusively or predominately in Spanish. One set of EP parents used Spanish among themselves only when Spanish-dominant speakers were present; another reported using both English and Spanish. These four parents were second-generation speakers. Children in all households had regular contact with Spanish-dominant family, neighbors and friends.

EP families were middle class, belonged to the same SN and had two children. ${ }^{3}$ Three sets of EP parents were born on the Mexican side of the Chihuahua-Texas border, had spent most of their life commuting between Juárez and EP, and had relocated permanently $<12$ years prior. All LV families were working-class first-generation immigrants to the USA. The family with the longest history of residence had lived in LV for 21 years; the most recent arrivals for only two. Three families belonged to the same network, and two belonged to a different network in the same neighborhood. All LN families were working-class first-generation immigrants, had lived in another state before moving to Nebraska and belonged to the same network. All EP fathers had been born in the Chihuahua-West Texas region. Two attended school in EP, two were born in EP but lived in Juárez until middle school. One relocated to EP as an adult. Three EP fathers held admin- 
istrative positions, and two worked in maintenance. All LV and all LN fathers were L2 speakers of English. LV fathers were employed in the industrial and service sectors. LN fathers worked in the construction and industrial sectors.

\section{Results}

Before presenting the results of the analysis of their SNs, it is important to address respondent attitudes about use and transmission of Spanish. Respondents in the three communities held positive to very positive attitudes towards Spanish use in their community, and all articulated positive attitudes towards transmission of Spanish to their children. However, although they expressed positive views about use of Spanish in their community, four EP mothers believed that the local variety of Spanish was somehow deficient or improper. Two EP mothers believed that it should not be taught in school, and that only oral transmission was desirable. One second-generation speaker in this subgroup did not transmit the language to her children. One LV mother believed that only oral transmission was desirable. All mothers in the LN group believed that Spanish literacy was desirable for their children. Regarding use of Spanish, LN respondents reported using more Spanish with their children than mothers in the other two communities. Data were obtained by asking mothers what language or languages they most commonly used while engaging with their children in 15 common household interactions. Overall, EP mothers reported using more English, or both languages with their children. The fact that respondents in LN, the community with the lowest ethnolinguistic vitality, reported more use of Spanish may be due in part to the effect of three concurrent factors that involve mother's history of language acquisition, her SN and the family's socio-economic situation. All LN mothers were adult L2 learners of English with limited opportunities to interact with adults in their L2; their closest networks included exclusively or almost exclusively native speakers of Spanish. The three LN mothers who worked outside the home interacted in English with managers and co-workers, but could perform their work without using their L2. LN children did not participate in activities that are common in middle-class families, and require money, transportation and parents' schedule flexibility - for example, sports clubs, music lessons, scouting, cheerleading. Most after-school and leisure activities for LN included interactions with other Latino families in their neighborhood, school or church.

On the other extreme, all mothers in EP, the community with the highest ethnolinguistic vitality for Spanish, were fully bilingual, and held professional positions that required command of both languages. EP mothers participated in interactive networks that included a larger number of English speakers. Several EP children participated or had participated in activities that involved both expenditure of resources and contact with families outside their neighborhood and immediate network of interaction. EP was the only community in which mothers did not report higher English competence for their spouses than themselves. Overall, mothers reported using more Spanish than their children. LN mothers reported most commonly speaking Spanish to their children in $86 \%$ of common household interactions, and 76\% use of Spanish when their children addressed them. LV mothers reported $60 \%$ use of Spanish, and $45 \%$ for their children. Lowest use of Spanish was reported in EP, with $43 \%$ for mothers and $33 \%$ for children. 


\section{Primary language of exchange}

According to their report, participants spoke mostly Spanish with $81 \% 4$ of the 119 individuals identified as their closest friends and family not living in their household. They spoke mostly English with only 7\% of named individuals, and both languages with 12\% of actors. EP respondents reported using more English or both $-20 \%$ and $24 \%$, respectively. EP respondent R5 stands out from all other participants in the study, in that, although fluent in Spanish, she spoke English with 63\% of her closest friends and family not living in her household, and spoke English with her sons and husband unless a Spanish-dominant speaker was present. During one of the interviews conducted in her home, $R 5$ reported that she had acquired both languages as a child, but that she had lost fluency in elementary school. She had reacquired Spanish as an adult, when she married a man with a Spanish-dominant family and got a job in which she needed to use it daily, but did not speak it at home-although, as observed by the researcher, her family regularly consumed TV and music in Spanish. It will be argued here, then, that for R5 Spanish was not so much a home language, as a community language.

Use of Spanish reported by EP respondents in their personal networks was high$56 \%$, but was lower than that of respondents from LV and LN. LV respondents reported almost exclusive use of Spanish when interacting with their closest friends and family outside their household-97\%. Only one LV mother reported using both languages with one of the members of her network. No respondent in LV reported using mostly English with any network actor. Similarly, LN respondents reported almost exclusive use of Spanish when interacting with the members of their closest networks - 95\%. Only LN respondent $R 1$ reported using both languages with her (female) cousins, who were secondgeneration MexAm. LN respondent $R 4$ reported speaking English with her boss and her priest, whom she identified not as friends, but as individuals she saw more than twice in a normal week. In particular, she explained that she spoke both languages with her priest because he was also her English teacher, but that she mostly spoke Spanish with him outside of class. No use of English was reported by LN mothers in interactions with close friends and relatives.

An important clarification should be made here. The idea that these 15 women did not use English in their daily lives is incorrect. EP respondents were fully bilingual and could live their lives entirely in English, had they wished to do so. They did, in fact, live an important part of their professional and community lives in this language. Although not fully bilingual, the three LN respondents who worked outside the home interacted daily in English with managers and co-workers. Even respondents with the lowest levels of English proficiency in LN and LV interacted in that language with doctors, teachers, neighbors, shopkeepers and other community members. Further, high use of Spanish by LV and LN participants did not preclude them from wishing to learn English. All but two LV respondents, and all LN participants were taking or had taken English classes, and all considered the acquisition of English as fundamental for economic mobility. For all participants in this study, the acquisition of English by their children was given. What these results do suggest, however, is that for 14 of the 15 participants in this study Spanish was the language of exchange in their closest circle of interaction. As will be argued below, the fact that Spanish was the most commonly used language in the networks in which these 
speakers relied upon most, has important implications regarding the access to community resources and linguistic/cultural maintenance and reproduction.

\section{Density}

Network density was measured by dividing the number of concrete exchanges by the number of possible exchanges. A concrete tie was understood as a tie through which the respondent had actually exchanged information, economic/material resources or emotional support. Under this definition, a density measure near 1 describes a closely bound network, in which a speaker relies and is relied upon by all other network members. A network density below 0.5 describes a network that offers mostly symbolic support. Table 1 summarizes these results. As shown in Table 1, only 2 of the 15 respondents in this study - R2 in EP and R4 in LV, belonged to dense personal networks. It should be noted, however, that the network of LV respondent R4 had only two other actors beside herself. For other respondents in this study, the ties that bound them to their closest network of interaction beyond their home were mostly virtual or symbolic - that is, they felt that if needed, those ties could be used to exchange resources, but had not actually done so.

\section{Strength of ties}

An additional way to understand the structure of a SN is to look at the strength of the ties that bind its actors. In this study, it was expected that strength of network ties would help us identify potential sources of information and influence. As explained above, most participants perceived that the ties that bound them to their closest relatives and friends (not living in their household) were symbolic. This is to say, a tie through which the respondent and another network actor had not actually exchanged resources, but that the respondent believed she would/could activate if she needed to. The highest percentages of concrete ties - that is, ties through which the respondent and another network actor had actually exchanged resources - were found in the networks of $R 2, R 4$ and $R 5$ in EP-respondents with a longer history of residence in the border region. The lowest were found in the networks of $R 3$ and $R 5$ in LV - respondents with a shorter history of residence as compared to most respondents in the three communities. As Degenne and Forsé (1999) point out, both weak and strong network ties are forms of social capital, but perform dif-

Table 1. Network density.

\begin{tabular}{llllll}
\hline El Paso & \multicolumn{3}{l}{ La Villita } & Lincoln & \\
\hline R1 & 0.20 & R1 & 0.30 & R1 & 0.24 \\
R2 & 0.82 & R2 & 0.50 & R2 & 0.39 \\
R3 & 0.33 & R3 & 0.04 & R3 & 0.46 \\
R4 & 0.53 & R4 & 0.85 & R4 & 0.42 \\
R5 & 0.35 & R5 & 0.04 & R5 & 0.20 \\
Average & 0.44 & Average & 0.34 & Average & 0.34 \\
Median & 0.35 & Median & 0.30 & Median & 0.39 \\
\hline
\end{tabular}


ferent functions. Strong ties tend to create closed self-sealing groups where information reaches all members rapidly. On the other hand, weak ties circulate information between one self-sealing group and another (Degenne and Forsé 1999,111).

\section{Level of integration to local, regional, national and transnational networks}

Before the start of data collection, it was expected that participation in local networks would indicate a respondent's integration to the local community as well as potential access to English-dominant and bilingual actors. It was also expected that respondents' participation in networks with Spanish-dominant actors in Mexico and other states in the USA would indicate family opportunities for exposure to monolingual varieties, linguistic re-contact and socialization to Mexican cultural norms and practices (Sánchez 2007). Participation in these networks was determined by asking respondents about the physical location of each actor in their network. Overwhelmingly, the networks analyzed in this study involved face-to-face interactions. Seventy-eight per cent of network actors lived in the same community as the respondent. Six per cent lived in the same region, and another six per cent lived in another US state. The $10 \%$ of network actors who lived in Mexico were relatives of the respondents who had the shortest history of residence in the USA ( $R 2$ and $R 3$ in LN, R5 in LV). Most participants in the three communities had relatives and acquaintances that lived in Mexico, but with the exception of the three respondents mentioned above, they did not identify them as part of their closest network of interaction.

\section{Degree of gender segregation}

In this study, degree of gender segregation was measured by determining the percentage of female and male actors in the respondents' closest network beyond their household. Male actors were further classified as related or unrelated to the respondent. Gender segregation, or gender separation, will be understood here as the voluntary association of individuals in same-sex peer groups (Cameron 2005). A high degree of gender segregation by network would suggest intra-network ways of speaking and not speaking, specifically female modes of information distribution, and forms of prestige, solidarity and influence not necessarily corresponding to those existing outside the network. In his investigation of the effects of gender segregation on the speech of individuals of the same dialect community, Cameron $(2005,53)$ finds that patterns of separation between genders fluctuate across different life stages.

Seventy-four per cent of all network actors in the three communities included in this study were female. Of the $26 \%$ of male actors identified by respondents, only four were not relatives. EP respondents $R 2$ and $R 3$ identified two male neighbors $(R 2)$ and two male co-workers $(R 3)$ as members of their closest personal network. LN respondent $R 4$ identified her boss and her priest as two unrelated males whom she saw more than twice in a normal week, but not as her close friends. These results do not mean, of course, that the 15 participants in this study did not interact with males in their everyday lives. What they do suggest, however, is that the individuals in whom these respondents relied upon most outside their household were women. This would seem to support Cameron's observation that "gender segregation differs from socio-economic segregation in that gender segregation is mixed with gender intimacy" (Cameron 2005, 25). 


\section{Discussion}

The preceding has been an analysis of mother's SN as related to Spanish maintenance in a group of MexAm families in three communities in the USA. The goal of this study was to examine potential opportunities for Spanish use by children as well as potential sources of influence and information about the benefits and drawbacks of linguistic maintenance for the mother. A prediction was made that tightly bound, dense networks of competent speakers of Spanish would foster use and transmission of Spanish.

Spanish was the primary language of exchange for 14 of the 15 networks described. Respondents spoke mostly Spanish with $81 \%$ of the 119 individuals identified by them as their closest friends and family not living in their household. They spoke mostly English with only $7 \%$ of named individuals, and used both languages with $12 \%$ of network actors. Greater use of English or both languages was reported in EP, the community with the highest ethnolinguistic vitality for Spanish. No use of English was reported by any of LV or LN respondents when interacting with close relatives and friends. These results do not mean that respondents did not use English in their daily lives, but rather that in their closest circle Spanish was the most viable language to access symbolic and material resources.

Gender segregation or gender separation was observed in all networks analyzed in this study. Seventy-four per cent of all network actors in the three communities were female. Of the $26 \%$ of male actors, only four were unrelated to the respondents. This points to intra-network, specifically female modes of information distribution, and forms of prestige, solidarity and influence. The articulation of age and gendering described by Cameron (2005) was also observed. Respondents tended to contribute or take resources from their network according to their stage in life, their position in their extended family, and their length of residence.

Although not dense, the personal networks described in this study were multiplex. In fact, in all networks, most close relatives who lived in the same city knew all or most of the respondent's closest friends. However, results suggest that most of the participants in this study perceived the members of their closest network as sources of symbolic, rather than concrete, support. The highest density scores were found in EP. A higher degree of multiplexity was observed in EP and LN than in LV. EP respondents had a deeper sense of rootedness. Even though their relocation officially involved moving to another country - themselves, their parents or their grandparents, they had in fact been living in one binational border region for at least three generations. ${ }^{5} \mathrm{LN}$ families had relocated from another state in search of employment, greater quality of life, and, importantly, to join pre-existing networks of extended family. This contrasts with LV respondents, who had limited contact with individuals in other parts of the city, perceived their neighborhood as unsafe and preferred to limit their contact with people outside their household because of a perceived threat to their personal safety. Seventy-eight per cent of all actors lived in the same community as the respondent.

If a parent's personal network has the potential to influence her views on language transmission, how does this occur? It will be argued here that this takes place through the same mechanisms described by Cochran (1990) for modeling of other parental behaviors. Indeed, data suggest that respondents perceived transmission of Spanish as one of a con- 
stellation of other parental duties. Actors in these 15 mostly female networks provided different types of support to the respondents, helping them co-construct their identity as mothers. In the case of the 13 first-generation mothers, interaction with female actors who had a longer history of residence helped them to become socialized to mainstream views on parenting, to the US school system, and to parenting in a minority-language setting. Additionally, network members influenced mothers' views by encouraging or criticizing parental decisions related to language use.

Actors who were parents themselves modeled behavior through positive and negative examples. In an equally important manner, many of the adults in these networks provided children not only with opportunities to use Spanish, but also with their own evaluations of language use and language users. In other words, these adults provided the children in these families with a social context for language use beyond their household.

The analysis presented here leads us to reformulate our original prediction in the following manner: Use and transmission of Spanish will be fostered in multiplex networks of competent speakers if Spanish is vested with social capital within the network - that is it is the most viable language to access resources. These findings must be generalized or rejected in future studies that include a greater number of participants, different types of families and different communities. The gendered nature of the networks described herein has implications for language planning and educational policy efforts in Latino communities. Institutions wishing to tap into these networks must take into account that the most effective flows of information in them are not top-down, but horizontal. In these networks credibility is based on shared experience, knowledge of Spanish and shared funds of knowledge that are most effectively accessed through traditionally female spaces and activities - for example, cooking, preparation of celebrations, religious rituals, home remedies, family budgets, teaching politeness and social obligations.

\section{Conclusion}

This study improves our understanding of the role of SNs in language maintenance because it highlights the gendered nature of intergenerational transmission and suggests the ways in which patterns of adult interaction impact children's opportunities to be socialized to and through the family language. This analysis advances our knowledge of the application of SNA to maintenance and shift because it offers a finer-grained analysis of exchange networks. This is especially relevant when trying to identify which network members are sources of influence regarding Spanish transmission.

For the 31 children whose mothers participated in this study - as for many children growing up in first- and second-generation Latino households, the major challenge for maintenance will not be lack of exposure to Spanish, but relevance. What social and cultural capital will be vested in Spanish as they go on to build their own personal histories? To the extent that bilingualism is a goal for these families, Spanish must remain a viable alternative as these children go on to build their own networks. This is the challenge presented to the adults in their lives. Ultimately, however, it will be a matter of a personal choice that will take place within the language ecology of the communities in which these children are growing up. 


\section{Notes}

1. Children's SNs, which are not the subject of the present discussion, are an equally important source of influence on household language dynamics, specially as children grow up and develop their own networks of interaction outside of the family.

2. The fathers in these households participated in child-rearing duties to varying degrees. The mothers, however, were the primary caregivers, and were implicitly or explicitly responsible for making most decisions about household language use, and about their children's interaction with peers and adults beyond the home. Other family arrangements are of course possible.

3. Socioeconomic status was determined by homeownership, parents' type of work and median income in the census tract where each family lived.

4. Percentages have been rounded to the nearest whole number.

5. Illustrative of this is the situation of El Paso respondents $R 1$ and $R 4$, whose networks had moved with them when they relocated from Ciudad Juárez. Only the families of the two second-generation speakers lived exclusively on the US side of the border. The other three El Paso respondents had family members of up to three generations living on either side.

\section{References}

Bortoni-Ricardo, S. M. 1985. The urbanization of rural dialect speakers: A socio-linguistic study in Brazil. Cambridge: Cambridge University Press.

Cameron, R. 2005. Aging and gendering. Language in Society 34: 23-61.

Cochran, M. 1990. Personal networks in the ecology of human development. In Extending families. The social networks of parents and their children, ed. C. Moncrieff, M. Larner, D. Riley, L. Gunnarsson, and C.R. Henderson. New York: Cambridge University Press.

Daming, X., W. Xiaomei, and L. Wei. 2008. Social network analysis. In The Blackwell guide to research methods in bilingualism and multilingualism, ed. L. Wei and M. G. Moyer, 263-74. Malden, MA: Blackwell.

Degenne, A., and M. Forsé. 1999. Introducing social networks. London: Sage.

De Houwer, A. 1999. Environmental factors in early bilingual development: The role of parental beliefs and attitudes. In Bilingualism and migration, ed. G. Extra and L. Verhoeven, 75-95. Berlin: Mouton de Gruyter.

Eckert, P. 1988. Adolescent social structure and the spread of linguistic change. Language in Society 17: 183-207.

Fishman, J. A. 1991. Reversing language shift. Theoretical and empirical foundations of assistance to threatened languages. Philadelphia and Clevedon: Multilingual Matters.

Fishman, J. A. 2000. Reversing language shift: RLS theory and practice revisited. In Assessing ethnolinguistic vitality. Theory and practice, ed. G. Kindell and M. P. Lewis, 1-26. Dallas, TX: SIL International.

Gal, S. 1979. Language shift: Social determinations of linguistic change in bilingual Austria. New York: Academic Press. 
González, N., L.C. Moll, and C. Amanti. 2005. Introduction. In Funds of knowledge. Theorizing practices in households, communities and classrooms, ed. N. González, L. C. Moll, and C. Amanti, 1-28. Mahwah, NJ: Lawrence Erlbaum.

Granovetter, M. 1973. The strength of weak ties. American Journal of Sociology 78: 1360-80.

Hawe, P., C. Webster, and A. Shiell. 2004. A glossary of terms for navigating the field of social network analysis. Journal of Epidemiology and Community Health 58, no. 12: 971-5.

Lanza, E., and B.A. Svendsen. 2007. Tell me who your friends are and I might be able to tell you what language(s) you speak: Social network analysis, multilingualism, and identity. International Journal of Bilingualism 11, no. 3: 275-300.

Maguire, L. 1983. Understanding social networks. Beverly Hills, CA: Sage.

Matsumoto, K. 2010. The role of social networks in the post-colonial multilingual island of Palau: Mechanisms of language maintenance and shift. Multilingua 29, no. 2: 133-65.

Milroy, L. 1987. Language and social networks, 2nd ed. Oxford: Blackwell.

Okita, T. 2002. Invisible work. Bilingualism, language choice and childrearing in intermarried families. Amsterdam: John Benjamins.

Paldam, M. 2001. Social capital: One or many? Definition and measurement. In New Political Economy, ed. S. Sayer, 117-42. Oxford: Blackwell.

Potowski, K., and J. Matts. 2008. Interethnic language and identity: MexiRicans in Chicago. Journal of Language, Identity and Education 7, no. 2: 137-60.

Ripley Smith, L. 2002. The social architecture of communicative competence: A methodology or social-network research in sociolinguistics. International Journal of the Sociology of Language 153: 133-60. DOI: 10.1515/ijsl.2002.001

Sánchez, P. 2007. Cultural authenticity and transnational Latina youth: Constructing a metanarrative across borders. Linguistics and Education 18, nos. 3-4: 258-82.

Stoessel, S. 2002. Investigating the role of social networks in language maintenance and shift. International Journal of the Sociology of Language 153: 93-131.

US Census Bureau. (n.d.). 2006, 2007 and 2009 data release. American Community Survey. http://www.census.gov/acs/www/ (accessed February 16, 2010).

Velázquez, I. 2008. Intergenerational Spanish language transmission: Attitudes, motivations and linguistic practices in two Mexican American communities. PhD diss., University of Illinois at Urbana-Champaign.

Velázquez, I. 2009. Intergenerational Spanish transmission in El Paso, Texas: Parental perceptions of cost/benefit. Spanish in Context 6, no. 1: 69-84.

Walker, K. N., A. MacBride, and M.L.S. Vachon. 1977. Social support networks and the crisis of bereavement. Social Science \& Medicine 11: 35-41.

Wei, L. 1994. Three generations, two languages, one family: Language choice and language shift in a Chinese community in Britain. Clevedon: Multilingual Matters.

Zentella, A. C. 1997. Growing up bilingual. Oxford: Blackwell. 